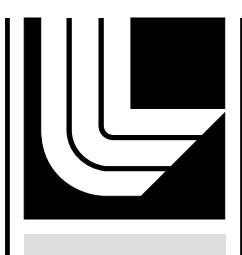

LAW RENCE LIVERMORE N A TION A L LABORATORY

An Accelerated Collaboration Meets with Beaming Success

A. U. Hazi

February 16, 2007 
This document was prepared as an account of work sponsored by an agency of the United States Government. Neither the United States Government nor the University of California nor any of their employees, makes any warranty, express or implied, or assumes any legal liability or responsibility for the accuracy, completeness, or usefulness of any information, apparatus, product, or process disclosed, or represents that its use would not infringe privately owned rights. Reference herein to any specific commercial product, process, or service by trade name, trademark, manufacturer, or otherwise, does not necessarily constitute or imply its endorsement, recommendation, or favoring by the United States Government or the University of California. The views and opinions of authors expressed herein do not necessarily state or reflect those of the United States Government or the University of California, and shall not be used for advertising or product endorsement purposes.

This work was performed under the auspices of the U.S. Department of Energy by University of California, Lawrence Livermore National Laboratory under Contract W-7405-Eng-48. 


\section{An Accelerated Collaboration Meets with Beaming Success}

$\mathbf{M}$ AINTAINING a smaller, aging U.S. nuclear weapons stockpile without underground nuclear testing requires the capability to verify and validate the complex computer calculations on which stockpile confidence is based. This capability, in turn, requires nonnuclear hydrodynamic tests (hydrotests) that can $\mathrm{x}$-ray stages of the implosion process, providing freeze-frame photos of materials imploding at speeds of more than 16,000 kilometers per hour. The images will yield important information on shapes and densities of metals and other materials under the extreme pressures and temperatures generated by the detonation of high explosives.

The Dual-Axis Radiographic Hydrodynamics Test (DARHT) Facility at Los Alamos National Laboratory is a two-arm x-ray imaging system that will provide such images, capturing the inner workings of a mock nuclear explosion with high resolution.

Scientists compare the radiographic images with computer models, examine the differences, and refine the models to more accurately represent weapon behavior.

One of DARHT's arms (now called DARHT-II) recently got a "leg up" through a collaboration of Lawrence Livermore and Los Alamos scientists, using a Livermore accelerator to test its subsystems and codes.

\section{Imaging the Unseen}

DARHT's two beamlines, set at right angles to one another, will generate two perpendicular images. These image pairs can be combined to yield quasi-three-dimensional pictures depicting the implosion process. The first-built arm of the DARHT Facility has an accelerator that generates a single 18-megaelectronvolt, 2-kiloampere pulse, lasting 60 nanoseconds. The second arm, DARHT-II, designed in a collaborative effort by Los Alamos, Lawrence Livermore,

An aerial view of the Dual Axis Radiographic Hydrodynamic Test (DARHT) Facility at Los Alamos National Laboratory shows the facility's two accelerators set at right angles to one another. (Image courtesy of Los Alamos.)

Reprinted from Science \& Technology Review; April 2006 UCRL-TR-228147

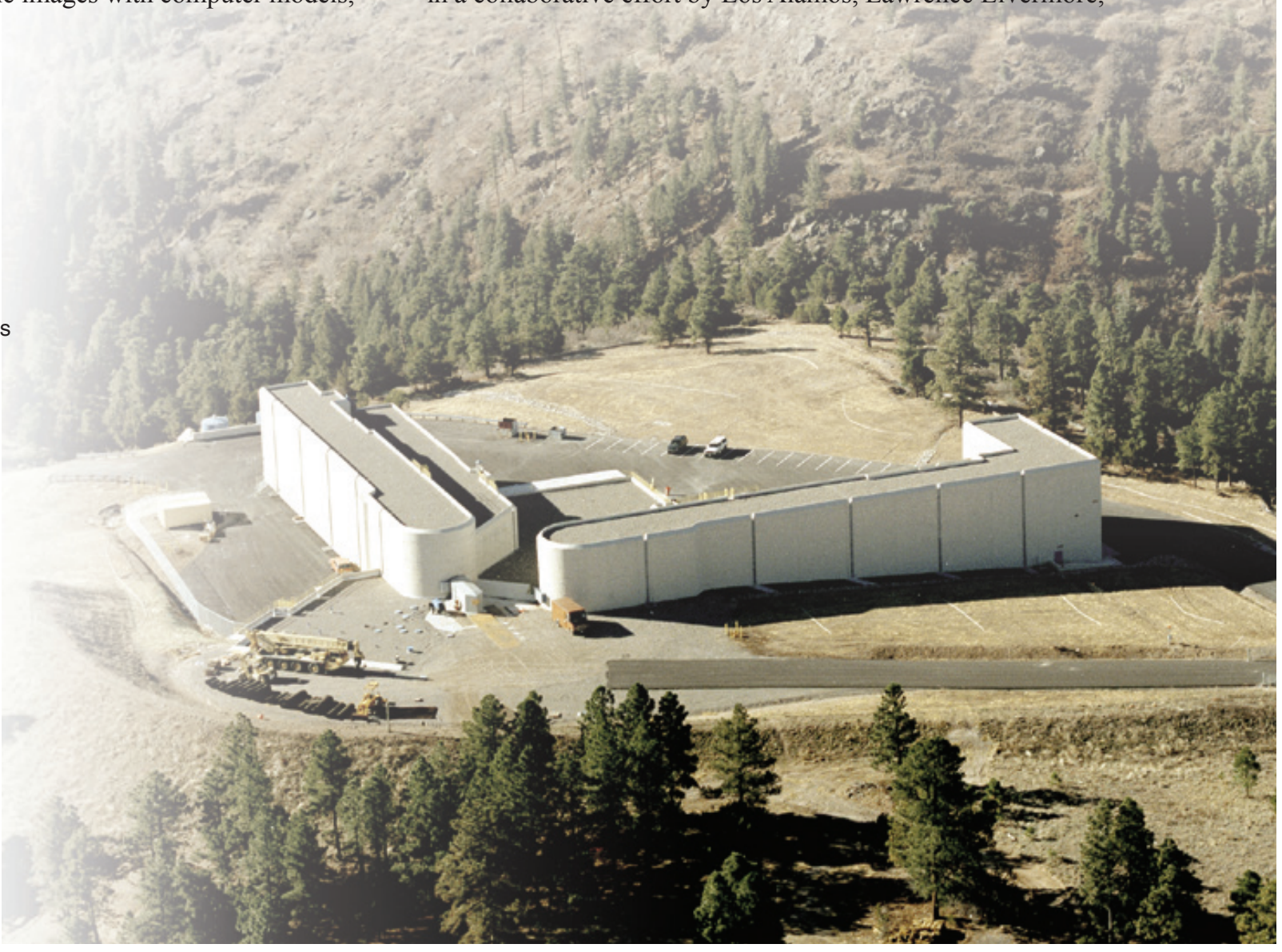


and Lawrence Berkeley national laboratories, generates a 20megaelectronvolt, 2-kiloampere pulse that will last comparatively much longer -2 microseconds.

DARHT-II's electron beam is first accelerated to the proper energy for the experiment. A Livermore-developed "kicker" system then chops four shorter pulses of variable pulse-width and spacing from this longer, second-arm pulse. These shorter pulses will allow the system to produce time-resolved x-ray images. The chopped pulses are tightly focused onto a small x-ray target made of a highatomic-number (high- $Z$ ) material such as tungsten. The target converts the high-energy electron beam into $\mathrm{x}$ rays, which emerge from the other side of the target. The $\mathrm{x}$ rays travel to and through the experimental object, which is being explosively compressed at velocities of many kilometers per second. The x rays are attenuated as they go through the object. For denser materials, fewer $\mathrm{x}$ rays will emerge from the other side. A segmented scintillator converts the remaining $\mathrm{x}$ rays to light, which is then lens-coupled onto a mosaic of large-area charge-coupled-device cameras.

\section{Collaborating on the Line}

While DARHT-II was undergoing refurbishment last year, Livermore scientists hosted Los Alamos personnel, so the visiting scientists could test its systems on Livermore's Experimental Test Accelerator-II (ETA-II). In particular, the beamline equipment and systems downstream from the electron accelerator were tested. The

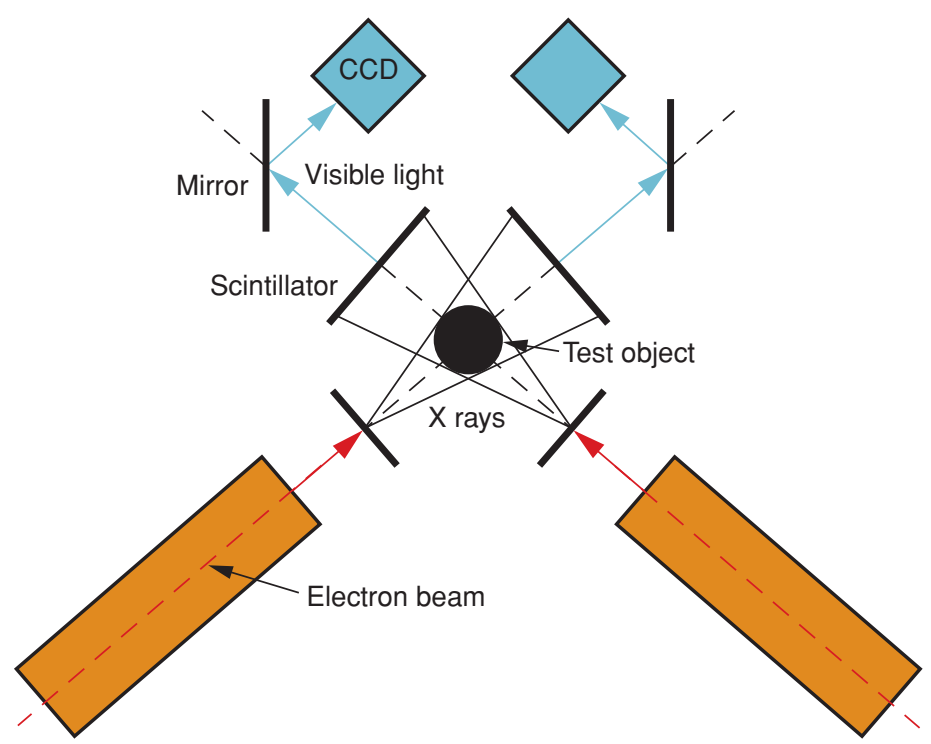

X-ray images from the two accelerator arms will be combined to yield quasithree-dimensional views of hydrodynamic experiments. The electron beams from the two accelerators will hit a metal target, which will produce $x$ rays that will pass through a test object. A scintillator will covert the $\mathrm{x}$ rays to visible light, which will then be directed to charge-coupled-device (CCD) cameras.

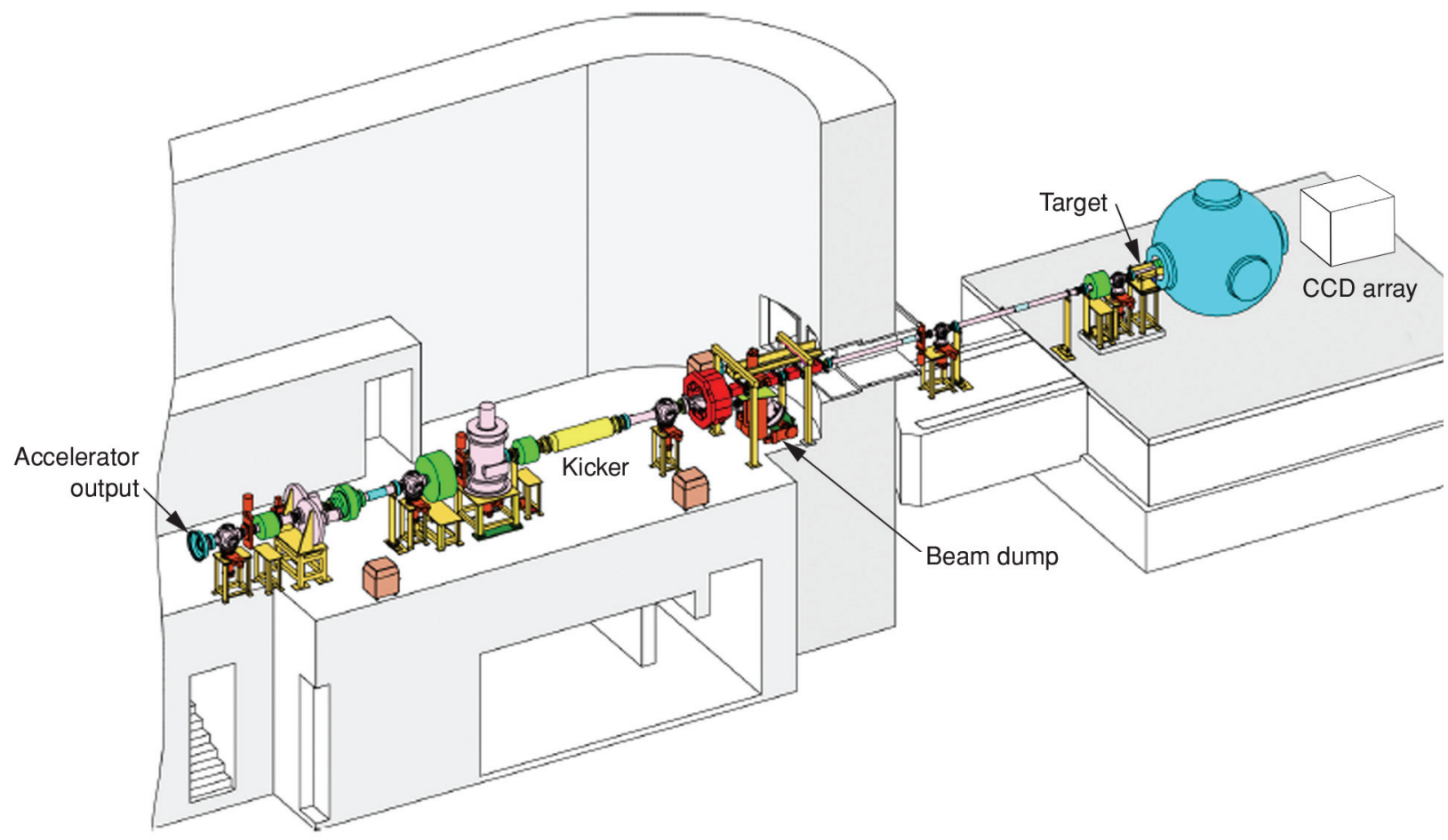

This schematic shows the downstream transport of DARHT's second beamline, from the output of the accelerator to the CCD cameras. 
Los Alamos-Livermore collaborators built a test bed on ETA-II, a high-repetition-rate accelerator designed to deliver high average power as well as high peak power.

"The tests proved very valuable," says physicist George Caporaso, who led the Livermore part of the collaboration. "They showed that the high currents required for long-pulse beam operation at Los Alamos could be successfully transported through the downstream beamline. The tests also allowed the teams to develop a predictive capability to tune the beamline, to establish the initial settings for future experiments, and to qualify hardware and software."

One initial question the teams had was whether the Los Alamos subsystems would "mesh" with the Livermore-built hardware. "We hooked everything up and checked to see how it all ran, including the beam diagnostics, and everything worked," says Caporaso. "Another question we had was, once we connected the Los Alamos diagnostic systems to ETA-II, would we be able to collect the data generated in the tests with this Los Alamos-Livermore combination of subsystems? Turns out, we could! The combined subsystems worked great."

The extensive dry runs provided assurance that DARHT-II's downstream beamline subsystems were ready for future experiments. The teams acquired information on the electron-beam parameters, such as current and energy, as the beam progressed through the downstream transport systems. They verified that the process for tuning the high-current electron beam, that is, getting just the right pulse shape and level, would work. "The DARHT Facility will be capable of generating 40 pulses a day for experiments; ETA-II generates 1 pulse per second. We were able to tune the current in real time with ETA-II," says Caporaso. The experiments also helped Los Alamos scientists perfect the computer algorithms that will be used to tune the beamline in the shortest number of shots.

Furthermore, the ETA-II test bed allowed Los Alamos scientists to operate the Livermore-designed kicker system and interface it to their data-acquisition system and diagnostics. The kicker uses electric and magnetic fields to manipulate the beam. When the kicker is turned off, the magnetic fields deflect the beam, and the beam is transported into a beam dump. Only when the kicker is turned on, will a short segment of beam travel onto the x-ray conversion target.

The DARHT collaborators addressed the challenge of how to focus the electron beam on a small area of the converter target in an optimum way. "A single beam pulse is normally powerful enough to blow a hole in the converter when it hits," says Caporaso. "With the second beamline operating, the target must survive long enough for four X-ray beams to emerge from the other side." The collaborators also worked on algorithms and schemes that would help them obtain the required spot shapes.

\section{Preparing for What's Next}

"The collaborative work on the downstream transport system was essential to help us prepare for long-pulse beam operation on DARHT-II at Los Alamos this summer," says Los Alamos's Ray Scarpetti, DARHT-II project director.

The teams from the two laboratories worked together to install the hardware, tune the magnets, model beam transport, and validate the codes. Los Alamos staff also had the opportunity to become familiar with the kicker system, including its controls and software, on an accelerator that allowed "real time" tweaking and fine-tuning. "The ETA-II test-bed effort was a successful technology transfer endeavor," says Caporaso. "Los Alamos people had an opportunity to become familiar with the Livermore-developed hardware and software, and the Livermore researchers had an opportunity to work with the Los Alamos equipment and codes. All in all, it was a successful exchange and collaboration for both labs."

—Ann Parker

Key Words: Dual-Axis Radiographic Hydrodynamics Test (DARHT) Facility, DARHT-II, Experimental Test Accelerator-II (ETA-II), stockpile stewardship, validation, $\mathrm{x}$ rays, $\mathrm{x}$-ray imaging.

\section{For further information contact George Caporaso (925) 422-7852 (caporaso1@IInl.gov).}

\section{DARHT Project Update}

The experimental campaign to test the downstream transport line and multi-pulse x-ray targets using a long pulse beam is nearing completion. These tests use an 8 megaelectronvolt, 1 kiloampere, 1.6-microsecond pulse from part of the DARHT-II accelerator to test the "kicker", beam transport and x-ray target options at roughly half power of the full accelerator. The objective is to provide an early evaluation of these systems prior to commissioning DARHT-II at the full energy in 2007 . The recent tests have been very successful. The kicker system produced four electron pulses almost immediately and generated four x-ray pulses from the first target configuration attempted. In subsequent testing, the measured spot sizes of the four x-ray pulses met the design specifications.

The fruitful Livermore-Los Alamos collaboration that worked so well during preparatory work at ETA-II at Livermore has continued during these tests at DARHT. Teams of Livermore scientists and technicians have traveled to Los Alamos nearly every week over a six-month period to support the campaign. With the recent test results in hand, the collaboration is highly confident that the DARHT-II project will successfully meet or surpass its technical goals. 